\title{
Effect of Epoxy Coating on Structural Steel Section under Tension
}

\author{
Shraddha Sharma, Mohan Kumar Gupta, Shashi Kant Jaiswal, Smita Gupta
}

\begin{abstract}
Structural steel connections are one of the most critical components of any steel structure as the cross-sectional area of steel sections reduces due to bolt holes. Failure of a structural connection may lead to failure of entire steel structure. Many researchers have tried to improve the connections previously by gluing fiber polymers at the connection. In this research glue or epoxy has been used around the bolt holes to simplify the process of using fiber polymers with steel. Epoxy is a combination of resin and hardener. It is proposed here to strengthen the structural steel connection in new structures and also in existing structures by applying a thin coat of suitable epoxy around the bolt hole. Thin steel plate with hole at the centre was tested under tensile load and results for ultimate load, breaking load, corresponding stresses and displacements obtained. Another steel plate with same geometry was then epoxy coated around the hole and same test was conducted on this specimen. Results for yield, ultimate, breaking loads and corresponding stresses and displacements recorded. The load-displacement curve is generated for both the cases and compared. The ultimate load bearing capacity of the plate increased in tension slightly after epoxy coating. Significant increase in breaking load observed as the thickness of epoxy layer was increased. Increase in the ductility of the composite plate is seen as increase in displacement is visible. There was considerable reduction of average stress around the center hole. The results indicate that structures can be safer against total failure and will give adequate warning before collapse.
\end{abstract}

Keywords: Epoxy, epoxy-coating, composite-section, stress reduction.

\section{INTRODUCTION}

Epoxy has been applied as a coating on structural steel to

* We would like to thank Government Chhattisgarh Swami Vivekanand Technical University for giving us platform to execute the research proposal based on the testing of unique use of epoxy glue as strengthening material and for supporting us financially.

Revised Manuscript Received on December 30, 2019.

* Correspondence Author

Shraddha Sharma, Associate Professor at the Department of Civil Engineering, Bhilai Institute of Technology, Durg, District Durg, India.

Dr. Mohan Kumar Gupta, Professor and Head at the Department of Civil Engineering, Bhilai Institute of Technology, Durg, District Durg, India.

Dr. Shashi Kant Jaiswal, Professor at the Department of Civil Engineering, Bhilai Institute of Technology, Durg, District Durg, India.

Smita Gupta, Assistant Professor at the Department of Structural Engineering, Chhattisgarh Swami Vivekanand Technical University, Bhilai, India.

(C) The Authors. Published by Blue Eyes Intelligence Engineering and Sciences Publication (BEIESP). This is an open access article under the CC BY-NC-ND license (http://creativecommons.org/licenses/by-nc-nd/4.0/) protect against corrosion, abrasion, turbulence and extreme temperatures. It is used as a glue to join parts of same metals and different metals as well by overlapping the pieces. In such cases bond and shear strength of epoxy is put to test. Then epoxy is used as a matrix system to create FRPs, CFRPs and GFRPs including fibers in them. The direction of these fibers decides the strength of reinforced plastics. And these FRPs, CFRPs and GFRPs are glued to different surfaces such as concrete, steel and other materials to form a composite to strengthen the existing structures. For joining the polymers to the existing structures again epoxies are used as glue.

It is generally observed that in structural steel sections failure occurs at connections near bolt holes mostly. So the scientists and engineers keep trying to strengthen the structural element at the connection itself by different means. The FRPs, CFRPs and GFRPs were glued at the connections around bolt holes to form composite sections. To strengthen the connection with FRP/CFRPs/GFRP is tedious as the surface preparation is done at the joint. The idea of using the glue itself in place of polymers is to make the process less cumbersome by just dipping the steel section ends in epoxy before putting bolts in them or placing a layer of epoxy around bolt holes and to take advantage of tensile strength of the glue. The important factor in making a composite section with the help of joining two materials by glue is that the composite section will function well till the glue bonding between two materials is intact. As soon as the materials debond due to failure of glue, the composite section fails. So ultimately well functioning of composite section depends on the strength of the glue. In this paper Epoxy glue has been used as a strengthening material with structural steel. The epoxy was coated around the bolt holes and tested for tensile loads. This type of use of epoxy before is not available in journals

\section{PAST RESEARCHES}

Yi Wang: Jun Deng et al.(2018) experimented with the steel plate with hole at the center and bonded with CFRP laminate to ascertain the effect of marine environment on the strength of the composite plate. The artificial environment resembling marine environment was generated by exposing the plate to wet dry cycles of water containing salts. Results for ultimate load, yield load, displacements, load - displacement and load-strain curves were compared for 180 and 90 wet dry cycles. The results showed the significant gain in bearing capacity and ductility, Mechanical properties degraded by 20 $\%$ for 180 WDCs and loss of stiffness in adhesive in 90 WDCs resulted in better bond durability [1]. 
Mahendra Kumar Madhavan; Vishwanath Sanap; et al. (2016) carried out experiments to assess the strength of composite sections made up of the steel angles wrapped around with Carbon-Fiber-Reinforced Polymer . Open angle -section was changed into closed section by wrapping the CRPF around the cross-section of angles that resulted in increased flexural stiffness and strength. The composite section and the angle section without CFRP wrapping underwent bending test at four points. The performance of the various factors measured in this experiment was the orientation of Carbon-Fibers, slenderness ratio, different number and thickness of CFRP layers. The different modes of failure for CFRP-reinforced angle sections were analyzed for different types of wrapping configurations. The results show the positive outcome as significant gain in strength and stiffness of steel angle when suitable configuration of CRPF and appropriate thickness and number of CFRP layers were used [2].

D. M. Penagos-Sanchéz; F. Légeron; et al. (2015) conducted a series of experiments on the utilization of CFRP sheets on steel elements to strengthen the net section area of steel sections under tension with similar parameters used by Mahendra Kumar et al. such as number of CFRP layers, different bond lengths and surface preparations. The steel plates with different arrangement of bolt holes and lap joints were used in specimens tested under tension. The observations included the initiation of failure and design load. Bond length was calculated for specimen bonded with CFRP. Final results obtained indicated no increase on design strength and significant increase in debonding strength in case of CFRP bonded steel sections. A small increase in elastic limit observed [3].

Song Zhou et al. (2013) conducted experiments and finite element simulations in ABACUS/Explicit to find out the effect of geometry of the member on the rupture of single-lap bolted composite joint. These joints were prepared by Vacuum Assisted Resin Injection and tested for material stiffness, strength and failure response. Two models showed the excellent resemblance with the experimental outcomes. The model generated in the software was found to be accurate, comprehensive and adequate. The software also assisted in determining the influences of geometry of the member on the rupture of composite section [4].

Yail J. Kim et al.(2012) presented the results of adhesively bonded double-lap butt joint. 43 specimens were treated with wet-dry cycles and freeze-thaw environmental conditions and then tested to determine load carrying capacity, failure mode, interface deterioration and durability performance. To efficiently perform this analysis, three-dimensional Finite element models were utilized. It was concluded that load carrying capacity increased through environmental exposures due to consolidation of epoxy in moisture present in the atmosphere. Existing environmental factors resulted in the change of failure mode cohesion to adhesion failure [5]. Interface deterioration increased due to environmental cycles.

Xiaocong He (2011) analyzed the researches on finite element analysis of adhesively bonded joints. Analyses were performed on ANSYS for static and dynamic loads, environmental behavior and fatigue loads. He concluded that ANSYS provides a platform to assist future applications of adhesively bonded metal joints by selecting a combination of various system parameters for testing and analyzing successful joint construction. This streamlined into the ability to perform ' $n$ ' number of tests on the software ANSYS on different combinations of adhesive joints and to select the appropriate combination for the real-time experiment. Due to ever-growing need of energy-efficient light weight constructions such as aircrafts and frames of vehicles, the techniques for assembling lightweight, unlike, different, with coatings and materials difficult to weld have been developed at a fast pace. The method of adhesive bonding is present since years, but it has really progressed scientifically and technically in last seventy five years. Aerospace industry contains more than fifty percent bonded structures such as in Boeing 787 and airbus A350. This epoxy bonding is currently used excessively due to ease of implementation, high corrosion and fatigue resistance, good damping characteristics, crack retardance, time and cost saving. Different joints can be made by adhesives such as lap, butt, double butt strap, bevel, peel etc. in tension. By utilizing the method of closed form equations or experiments, the various mechanical strengths of adhesively bonded joints can be acquired. Closed form equations give quick results. In the shear-lag analysis done by Volkersen, it was established that the adhesive fails in shear, and the adherent fails under tension [6]. Goland and Reissner (1944) were one of the first known who took into account the effects of rotation of the adherents. A total 210 research papers on adhesively bonded joints had been critically reviewed in his paper thus highlighting the improvements in analysis by Finite Element Method in adhesively bonded composite joints and the ongoing trends [7].

P.J. Grey et al. (2010) proposed a Global Bolted Joint Model which was precise and all inclusive. In order to model the bolts and composite layers, beam and shell elements were utilized. The GBJM was tested to explore the influence of the parameters such as bolt torque, bolt-hole clearance, secondary, tertiary bending in CFRP layers, distribution of load in case of multi-bolt joints and friction between layers. The model accuracy was proved by FEA and experimental results [8].

M.A. McCarthy et al. (2005) conducted experiments to explore the response of bolt-hole clearance on the stiffness of joint, stresses induced and the modes of failure of composite joints with bolts. They proposed a 3-Dimensional Finite Element model to simulate the response of bolt-hole clearance on the mechanical strength of composite joints with single-lap and single-bolt. Model was created in finite element non-linear analysis software MSC Marc environment. The accuracy of results of this analysis and the adequacy of model were proved by the experimental results and Finite Element solutions obtained in other similar project. Joint stiffness and surface strains experimental observations were cross-checked with results gathered from Finite Element Analysis by changing various factors such as mesh density, boundary conditions, element order, material modeling and type of analysis.

Published By:

Retrieval Number: B3576129219/2019@BEIESP

DOI: 10.35940/ijeat.B3576.129219

Journal Website: www.ijeat.org \& Sciences Publication
Blue Eyes Intelligence Engineering 
Secondary bending which occurred as a result of 3D variation in stress and strain was evaluated due to thickness variation and the observed mathematical singularities were highlighted. The validated model was used to examine the response of bolt-hole clearance on joint stiffness, induced stresses and failure initiation. Rise in the size of bolt-hole clearance was followed by overall reduction in stiffness of joint and reduced contact area [9].

D.A. Gasparini et al. (1990) conducted experiment to inspect the ease of joining steel to steel with adhesive. The mechanical properties of structural steel, properties of bonds and fabrication procedures were examined. The mechanical properties of adhesive depend on temperature. Adhesives are viscous at room temperature. Diffusion coefficient controls the rate at which water enters the adhesive. If bond between adhesive and steel are stronger then the joint undergoes cohesion failure. If adhesion between adhesive and steel is weaker then the join undergoes adhesion failure. The paper concludes that the lack of specifications and design code for adhesive makes the design process complicated. Satisfactory adhesive bonded steel to steel joint can be made for short term static load. Mechanical properties and fabrication technique controls the response of bonded joint. Low temperature fracture toughness and long term durability need further studies and experiments [10].

Pedro Albercht (1987) used adhesive and high strength friction grip bolts to bond the cover-plate and tension flange of a steel girder to prevent debonding. This experiment showed increase in fatigue life of girder by $20 \%$ than the welded cover plates [11].

R. Padma Priya (2015) carried out experiments to evaluate the response of cold formed steel angle tension members connected by bolts. Angle sections with different dimensions were tested by using single-line bolted connections. Several steel angle specimens lipped and plain bolted with high strength friction grip bolts of $10 \mathrm{~mm}$ diameter were tested in a Universal Testing machine. The thickness of the steel sheet used in this study was 2 and $3 \mathrm{~mm}$.Various types of connection failure, Load-displacement behavior were analyzed. The test results were validated by the values determined based on specifications recommended in codes AS/NZS 4600:2005 and BS 5950(Part V)-1998. Based on the test results, it is proposed in this paper that the net section strength of steel angle tension member is influenced by cross sectional area, thickness of the member and eccentricity of the connection [12].

Dr. M.K. Gupta and Dr. L.M. Gupta (2004) conducted experiments on three hot-rolled bolted steel angle specimens to assess the induced stresses on the angles at applied ultimate loads. The equations were predicted for the developed stresses and these stresses were validated by non-linear analysis on ANSYS. Specimens were made of steel equal-angles having dimensions $65 \mathrm{~mm}$ x $65 \mathrm{~mm}$ x 6 $\mathrm{mm}$, yield stress $250 \mathrm{~N} / \mathrm{mm}^{2}$ and ultimate stress $410 \mathrm{~N} / \mathrm{mm}^{2}$. The steel angles were connected to gusset plate by 2- bolts, 3bolts and 4-bolts in a row at each end to form three types of specimens respectively. The steel angle was modeled by quadrilateral shell elements with 6 DOFs at each node. The Von-Mises stresses were used to define yielding of the specimen. When a specimen is tested at design load under tension till failure, the connection undergoes non-linear plastic deformations. Non-linear analysis was adopted to include material and geometric non-linearity at the connections. Appropriate degrees of freedom were assigned to the bolt holes to represent the deformations. As the result of research work an equation for block shear strength was proposed. It was observed that:

- At Connections Von-Mises stresses were concentrated on connected leg only and having relatively low stress in unconnected leg.

- The distribution and magnitude of stresses around the holes at critical section were similar for 3-bolts and 4-bolts connections in a row.

- The net section failure of three and four bolt connections and block shear failure for two bolt connections were represented by the distribution of Von-Mises stresses.

- $\quad$ The Von-Mises stress diagram obtained by ANSYS showed high stresses along the critical section in connected and unconnected leg of steel angle in case of three and four bolt connection in case of two bolt [13].

Wu and Kulak (1993) presented the outcomes of tensile tests conducted on various double and single angle bolted specimens, to evaluate the influence of shear-lag on the net-section strength of the steel angle. The ultimate loads and stress-distribution obtained by experiment were compared with the values obtained by numerical finite element non-linear analysis. Considering these results some recommendations are made that differ considerably from design procedures currently used. Steel angles were modeled by quadrilateral shell elements with 6 DOFs at each node. The multi-linear isotropic stress-strain curve and non-linear Von-Mises Yield criteria was adopted for the analysis. Appropriate in-plane longitudinal and lateral degrees of freedom were awarded to the nodes of right half of hole surfaces where the bolts bear against the angle leg under tension. The material and geometric non-linearity was included in finite element analysis. A significant necking at the net section was observed at failure [14].

\section{METHODOLOGY}

A tensile test was conducted on two types of steel specimens on a Universal Testing Machine to study the effect of epoxy coating around the hole. The steel plate used was mild steel grade Fe 250 having yield stress $250 \mathrm{~N} / \mathrm{mm}^{2}$ and ultimate stress $410 \mathrm{~N} / \mathrm{mm}^{2}$. The different steel specimens were made from the same steel plate with same dimensions having a hole of same size at the center of the plate. Hole represents the bolt hole as well as specifies the location of failure. One plate was epoxy coated around the hole on both sides and one was without epoxy coating. 
The dimension of plate without epoxy as well as with epoxy coat measured accurately with Vernier Caliper.

The sizes of the plates were $300 \mathrm{~mm} \times 80 \mathrm{~mm} \times 2 \mathrm{~mm}$ and $300 \mathrm{~mm} \times 82 \mathrm{~mm} \times 1.7 \mathrm{~mm}$, diameter of hole at the centre was $16 \mathrm{~mm}$. The total thickness of epoxy coat on both sides of plate was $3 \mathrm{~mm}$ in one specimen and $5.9 \mathrm{~mm}$ in other around the centre hole. Epoxy used was Huntsman's Standard Epoxy Glue Araldite. Each specimen was tested till failure i.e. breaking load. The test conducted was load verses displacement type. All the specimens failed due to net section failure at the location of the hole. First the crack in epoxy appeared before it debonded from the plate in Test 2. Epoxy yielded first in Test 3, and then debonded just before breaking. The results were recorded for ultimate load, breaking load and corresponding stresses and displacements. Load Vs displacement curve generated for each plate. The results of steel plate with epoxy coating and without epoxy were compared.

The ultimate load, breaking load and corresponding displacements for steel specimen without and with epoxy coating were:

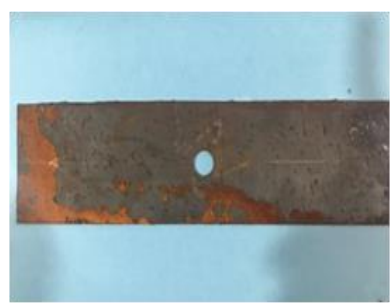

Fig. 1: Test-1

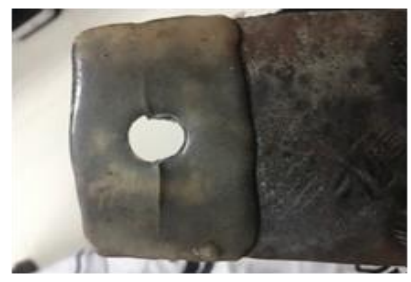

Fig. 3: After Failure

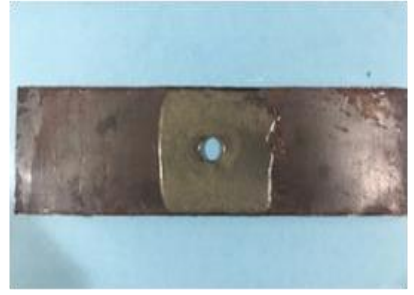

Fig. 2: Test-2

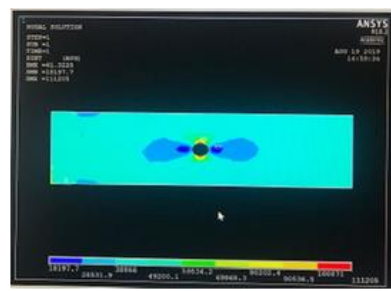

Fig. 4: Simulation in ANSYS

Table-I: Observations

\begin{tabular}{|c|c|c|c|c|c|c|c|c|}
\hline Test & $\begin{array}{c}\text { Cross } \\
\text { Sectional } \\
\text { Area of } \\
\text { Steel } \\
\text { Plate } \\
\text { mm }^{2} \\
\text { (Ags) } \\
\end{array}$ & $\begin{array}{c}\text { Cross } \\
\text { Sectional } \\
\text { area of } \\
\text { epoxy } \\
\text { layer } \\
\text { mm }^{2} \\
\text { (Age) }\end{array}$ & $\begin{array}{l}\text { Ultimate } \\
\text { Tensile } \\
\text { Load } \\
\text { kN (Pu) }\end{array}$ & $\begin{array}{c}\text { Ultimate } \\
\text { Tensile } \\
\text { Strength } \\
\mathbf{N} / \mathbf{m m}^{2} \\
\left(p_{u}\right)\end{array}$ & $\begin{array}{c}\text { Displacement } \\
\text { at ultimate } \\
\text { load } \\
\text { mm }\end{array}$ & $\begin{array}{c}\text { Maximum } \\
\text { Displacement } \\
\text { mm }\end{array}$ & $\begin{array}{c}\text { Breaking } \\
\text { load } \\
\text { kN } \\
(\mathbf{P b})\end{array}$ & $\begin{array}{c}\text { Breaking } \\
\text { Strength } \\
\mathbf{N} / \mathbf{m m}^{2} \\
\left(\mathbf{p b}_{\mathbf{b}}\right)\end{array}$ \\
\hline 1 & $\begin{array}{c}80 \times 2 \\
160 \mathrm{~mm}^{2}\end{array}$ & 0 & 43.4 & 271.250 & 12 & 17.6 & 22.2 & 138.750 \\
\hline 2 & $\begin{array}{c}80 \times 2 \\
160 \mathrm{~mm}^{2} \\
\end{array}$ & $\begin{array}{c}80 \times 3 \\
240 \mathrm{~mm}^{2} \\
\end{array}$ & 44.1 & 275.625 & 13.8 & 18.2 & 23.8 & 148.750 \\
\hline 3 & $\begin{array}{c}82 \times 1.7 \\
139.4 \\
\mathrm{~mm}^{2}\end{array}$ & $\begin{array}{l}80 \times 5.9 \\
472 \mathrm{~mm}^{2}\end{array}$ & 41 & 294.118 & 29.1 & 29.4 & 40.8 & 292.683 \\
\hline
\end{tabular}

Modulus of elasticity for mild steel was taken as $2 \times 10^{5}$ $\mathrm{N} / \mathrm{mm}^{2}$. The value of tension modulus for epoxy was taken from the specifications available as $1999.997 \mathrm{~N} / \mathrm{mm}^{2}$.

$\mathrm{P}=$ Load resisted by steel specimen

Ps = Load shared by steel plate in composite section

$\mathrm{Pe}=$ Load shared by epoxy in composite section

$\mathrm{p}_{\mathrm{s}}=$ stress in steel

$\mathrm{p}_{\mathrm{e}}=$ Stress in epoxy in composite section

Es $=$ Modulus of elasticity of steel

Ee $=$ Modulus of elasticity of epoxy

Ags $=$ Gross area of steel

Age $=$ Gross area of epoxy

$\mathrm{p}_{\mathrm{s}}=\mathrm{Ps} / \mathrm{Ags}$

$\mathrm{p}_{\mathrm{e}}=\mathrm{Pe} / \mathrm{Ee}$

$\mathrm{Ps}+\mathrm{Pe}=\mathrm{P}$ $\mathrm{p}_{\mathrm{e}} / \mathrm{Ee}=\mathrm{p}_{\mathrm{s}} / \mathrm{Es}$

Average Stress $=\mathrm{P} /($ Ags + Age $)$

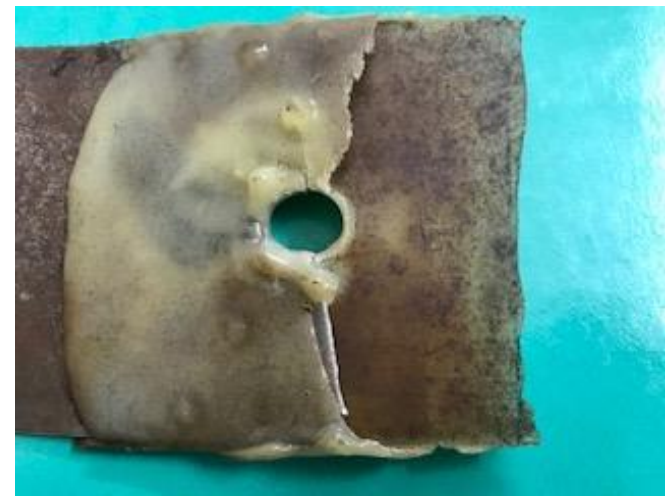

Fig. 5: Test-3 After Failure 


\section{RESULT}

1. The value of ultimate load, breaking load and displacement has increased in case of steel plate with epoxy coat around the hole at the center.

2. The ultimate load capacity has increased by $700 \mathrm{~N}$. Increase in breaking load was $1600 \mathrm{~N}$ in Test-2. In Test-3 breaking load increased considerably.

3. The increase in displacement at ultimate load was 1.8 $\mathrm{mm}$ and the increase in maximum displacement at total failure was observed as $0.6 \mathrm{~mm}$ in Test-2. Significant increase in displacement was observed at ultimate load and breaking load in Test- 3 when the thickness of epoxy was increased approximately three times the thickness of plate.

4. Ultimate strength is increasing in test 1 to test 3 from $271.250 \mathrm{~N} / \mathrm{mm}^{2}$ to $294.118 \mathrm{~N} / \mathrm{mm}^{2}$ as the thickness of epoxy layer increases and significant increase in breaking load and breaking stress was observed.

\section{DISCUSSION}

Increase in displacements shows gain in Ductility. The area under the load-displacement curve is increased in Test-2 i.e. the work done in breaking the specimen with epoxy coating is more as compared to the specimen without epoxy. A unique observation was seen in test 3 Load-displacement curve in which the thickness of epoxy was more than twice the thickness of steel plate. Epoxy debonded from one plate at one side but after cracking. At the other side epoxy reached to failure without debonding. The shape of the curve obtained is different from other two curves. ANSYS shows the maximum stress in red color near hole in lateral direction where the crack is visible on the epoxy coat of the specimen. The crack in all plates started from hole on both sides and extended towards edges of the plate. The average stresses decreased in epoxy coated specimen near the hole. Increase in displacement shows gain in ductility.

\section{CONCLUSION}

As the slight gain in ultimate load and significant increase in breaking load under tension is clearly visible, more investigations are required on different steel sections with varying thickness and different kinds of epoxies. This experiment is done with the commonly used epoxy as glue. Epoxies specially made for structural steel may give better results. The crack in epoxy shows that it successfully reached failure before debonding from the steel surface. In a connection and in whole structure each bolt hole would be able to bear little extra load and the cumulative effect of all epoxy coated bolt holes will result in improved performance of the structure. The results show significant gains in ultimate and breaking loads of the specimen indicating that if this approach is used for existing and new structures the structure will be safer against the total failure and will give adequate warning before collapse. This proposal will be a benefit to the existing structures that needed repairs.

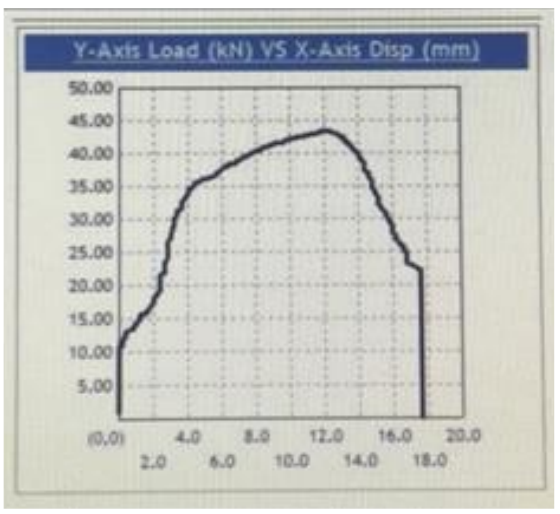

Fig. 6: Test-1 Load-displacement Curve
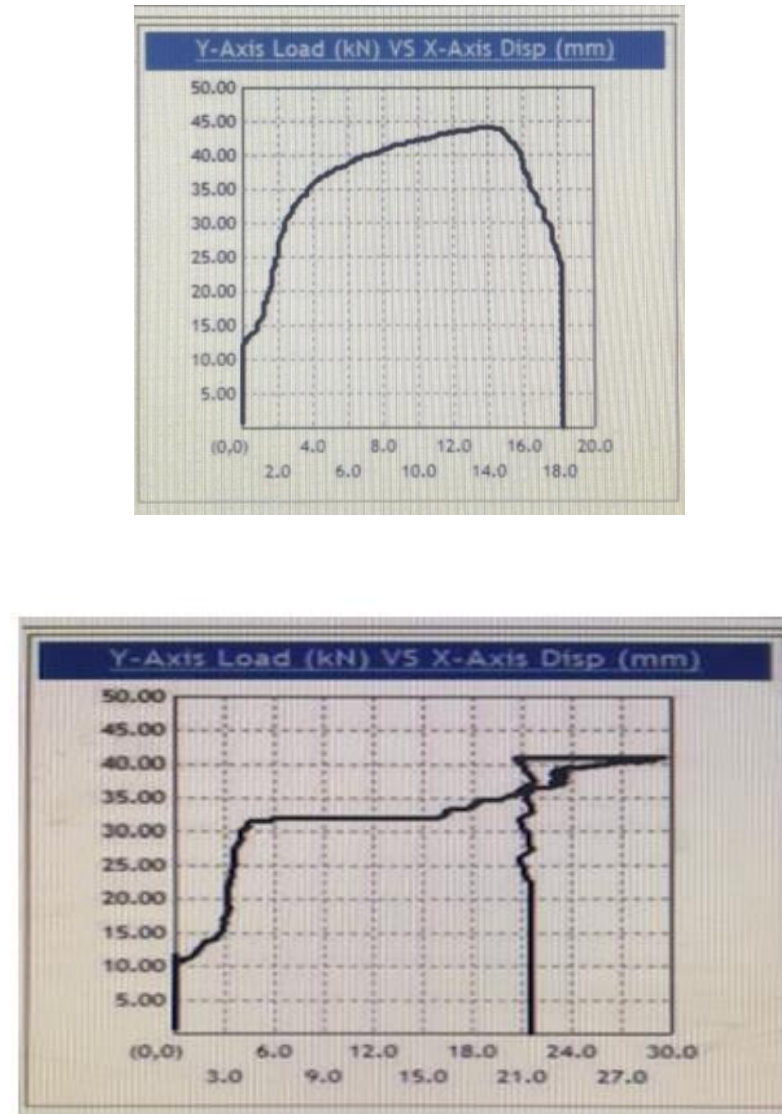

Fig. 7: Test-2 Load-displacement Curve Fig. 8: Test-3 Load-Displacement Curve

\section{FUTURE SCOPE}

Suitable epoxy and the appropriate thickness of epoxy layer and plate can be identified to strengthen the structural steel connection through experiments. Behavior of different epoxy coated steel sections such as angle; channel etc. can be studied by experiments and validated by the software. Based on these results appropriate relation between the geometry of the section, thickness of epoxy layer and net section strength of epoxy coated steel sections can be established. Equation relating total elongation, gauge length and cross-sectional area can be predicted. The epoxy coated sections can be tested in compression and bending also.

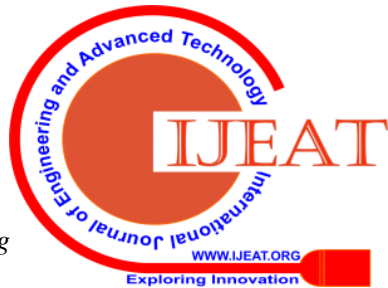




\section{REFERENCES}

1. Yi Wang; Y Zheng, J Li, L Zhang, Jun Deng et al., 2018, "Experimental study on tensile behavior of steel plates with centre hole strengthened by CFRP plates under marine environment", International Journal of Adhesion and Adhesives, volume 84, August 2018, pages 18-26.

2. Mahendra Kumar Madhavan; Vishwanath Sanap; Riteshkumar Verma and Sivaganesh Selvaraj, 2016 "Flexural Strengthening of Structural Steel Angle Sections Using CFRP: Experimental Investigation”, ASCE, J. Compos. Constr., 2016, 20(1): 04015018-(1-10).

3. D. M. Penagos-Sanchéz; F. Légeron; M. Demers; and S. Langlois, 2015, "Strengthening of the Net Section of Steel Elements under Tensile Loads with Bonded CFRP Strips", American Society of Civil Engineers. J. Compos. Constr., 2015, 19(6): 04015007-(1-12).

4. Song Zhou, Zhenqing Wanga, Jiansheng Zhou, Xiaodi Wu, 2012, "Experimental and Numerical Investigation on bolted composite joint made by vacuum assisted resin injection", ELSVIER, Composites: Part B 45 (2013) 1620-1628

5. Yail J. Kim, Mozahid Hossain, Isamu Yoshitake, "Cold region durability of a two-part epoxy adhesive in double-lap shear joints: Experiment and model development", ELSVIER, Construction and Building Materials, 36(2012) 295-304.

6. Xiaocong He, 2011, "A review of finite element analysis of adhesively bonded joints", International Journal of Adhesion \& Adhesives, 31 (2011) 248-264.

7. Goland M, Reissner E. J Appl. Mech 1944; 11:A17.

8. P.J. Grey, C.T. McCarthy, 2009, “A global bolted joint model for finite element analysis of load distributions in multi-bolt composite joints", ELSVIER, Composites: Part B 41(2010) 317-325.

9. M.A. McCarthy, C.T. McCarthy, V.P. Lawlore, W.F. Stanley, 2005, "Three-dimensional finite element analysis of single-bolt lap composite bolted joints: part I - model development and validation", ELSVIER, Composite Structures: 71 (2005) 140-158.

10. D.A. Gaspirani, Member ASCE, H. Nara, J. Andreani, C. Boggs, D. Brewer andP. Etitum, 1990, "Steel to steel connections with adhesives", ASCE, Journal of Struct. Eng. 1990, 116(5) 1165-1179.

11. Pedro Albercht, 1987, "Fatigue Strength of Adhesively Bonded Cover Plates", ASCE, J. Struct. Eng., 1987, 113(6): 1236-1250.

12. R. Padma Priya, 2015, "Experimental Study on Behaviour of Bolted Cold-Formed Steel Angles under Tension", Asian Journal of Civil Engineering (BHRC) Vol. 16, No. 7 (2015) pages 967-975.

13. Gupta, Mohan and Gupta, L. M. 2004 "Evaluation of stress distribution in bolted steel angles under tension", Electronic Journal of Structural Engineering, volume 4, pp 17-27.

14. Wu, Y. and Kulak, G.L. 1993 "Shear Lag in Bolted Single and Double Angle Tension Members", Structural Engineering Report No. 187, Department of Civil Engineering, University of Alberta, Edmonton, Canada.

15. IS 1608 : 2005, Metallic Materials - Tensile Testing at Ambient Temperature ( Third Revision )

\section{AUTHORS PROFILE}



Shraddha Sharma is ME in Civil Engineering with specialization in Structural Engineering from MBM Engineering College Jodhpur, presently working as Associate Professor, with 15 years of experience in teaching and 4 years experience on field. Number of publications 13 in conferences and journals, Guided many M. Tech. and BE projects, Member of Institution of Engineers India, Life Member of Indian Association for Computational Mechanics, Life Member of Indian Association for Structural Engineering, Life Member of Indian Society for Technical Education, Faculty development and Short term training program 13 and 1 guest lecture to the author's credit. She was Member of Board of Studies, CSVTU Bhliai.



Dr. M.K. Gupta is Ph.D. in Steel Structures from VNIT, Nagpur, presently working as Professor and Head with 25 years of experience. Number of publications 35 in conferences and journals, Guided Ph.D., M. Tech. and BE project He is Life Member of Steel Development and Growth, Institution of Engineers India, Indian Association for Structural Engineering, Indian Society for Technical Education and Indian Society for Wind Engineering. He has delivered 30 invited guest lectures in different institutions and organizations. He has attended 15 and organized 15 workshops / Faculty Development Program, Short term training program and conferences. Dr Gupta is PhD supervisor of
Government Chhattisgarh Swami Vivekanand Technical University, Bhilai, Chhattisgarh, India and Member of Board of Studies, CSVTU Bhilai.

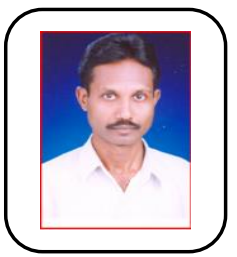

Dr. S.K. Jaiswal is Ph. D. in Water Resources Engineering from Chhattisgarh Swami Vivekanand Technical University, Bhilai (C.G.).Presently Professor with 27 years of experience in the Department of Civil Engineering, Bhilai Institute of Technology, Durg. Number of publications 16 in conferences and journals, Guided Ph.D., M. Tech. and $\mathrm{BE}$ projects. $\mathrm{He}$ is Life Member of Institution of Engineers India, Indian Society for technical Education, Indian Water Resources Society, Indian Water works Association. Faculty development and Short term training program 10 attended to the author's credit. Delivered 7 invited talk/guest lectures. He has conducted 6 FDP / STTP / Seminar / symposium. Dr. Jaiswal is $\mathrm{PhD}$ supervisor of Government Chhattisgarh Swami Vivekanand Technical University, Bhilai, Chhattisgarh, India and Member of Board of Studies, CSVTU Bhilai.

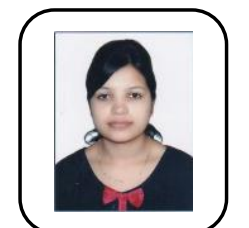

Ms. Smita Gupta is M. Tech. in Structural Engineering from VIT, Chennai (C.G.), presently working as Assistant Professor in the Department of Civil Engineering, Chhattisgarh Swami Vivekanand Technical University, Bhilai with two years of teaching experience. Number of publications 02 in conferences and journals, Guided M. Tech. and BE projects, and Short term training program 06 attended to the author's credit. 